\title{
Alterations in the Activity of Acetylcholine Esterase in the Dragonfly Larvae of Bradinopyga Geminata under the Stress of Selected Textile Dyeing Effluents
}

\author{
Thangaraj A ${ }^{1 *}$, Muralidharan $\mathbf{S}^{1}$, Senthilkumar $\mathbf{S}^{1}$ and Moorthi $\mathbf{M}^{2}$ \\ ${ }^{1}$ Department of Zoology, Chikkaiah Naicker College, India \\ 2Department of Zoology, AVC College, India
}

*Corresponding author: A Thangaraj, MSc, M.Phil, Assistant Professor, PG \& Research Department of Zoology, Chikkaiah Naicker College, Erode-638004, Tamilnadu, India, Tel: 09965442599; E-mail: profthangaraj@gmail.com
Research article

Volume 1 Issue 5

Received Date: October 29, 2018

Published Date: November 19, 2018

DOI: $10.23880 /$ izab-16000129

\section{Abstract}

Textile dyeing effluents were considered as the major cause of aquatic pollution in India. Many studies on textile dyeing effluents (TDE) have proved that they inflict serious damage to aquatic ecosystems. Mingling of TDE to any water body poses a great threat to aquatic life which needs to be explored. In the present investigation the effluents samples from 6 different textile industries $\left(\mathrm{ST}_{1}, \mathrm{ST}_{2}, \mathrm{ST}_{3}, \mathrm{ST}_{4}, \mathrm{ST}_{5}\right.$ and $\left.\mathrm{ST}_{6}\right)$ of Pallipalayam area of Namakkal district were analyzed and impact on the activity of acetylcholine esterase were estimated in the larvae of B. geminata. It was interpreted from the results that TDE contain a lot of organic and inorganic pollutants comprising metals and chemicals. When the larvae of $B$. geminata exposed to these pollution loads, the homeostasis was seriously affected in terms of enzymes. It implies that TDE were not properly treated up to the world's standard norms and proved detrimental to aquatic biota.

Keywords: Textile Dyeing Effluents; Acetylcholine Esterase; Bradinopyga Geminata; Heavy Metals

\section{Introduction}

The confluence of textile dyeing effluent to the river Cauvery was a matter of serious concern for ages in Pallipalayam and adjacent areas. Innumerable textile dyeing industries were being operated in these regions letting off their effluents into the water bodies along with sewage drains. It was owing to meet the growing demands of textile products around the country. Variety of dyes, coloring agents and chemicals were being used in textile dyeing process. River Cauvery was the worst affected river by the textile dyeing effluent units of the Namakkal district. The TDE contains a range of dye stuffs including direct dyes, mordants, vat dyes, sulphur dyes, azo dyes, and fibre reactive dyes used generally in dyeing cellulose fibers [1]. Dyes cause a series of illness in organisms like allergic dermatoses, respiratory diseases, mutagenic and genotoxic effects by reactive dyes [2,3]. TDE induced embryo teratogenic effects were also noticed by Birhanli, et al. [4]. The auxiliary substances used in post dyeing process like detergents, starches and other chemicals induce the production of toxic metabolites and 


\section{International Journal of Zoology and Animal Biology}

were found to be poisonous for fish and other aquatic animals [5].

In addition to the dyes many harmful auxiliary chemicals such as $\mathrm{S}, \mathrm{C}_{10} \mathrm{H}_{8} \mathrm{O}, \mathrm{NO}^{3}, \mathrm{CH}_{3} \mathrm{COOH}$, soaps, enzymes, $\mathrm{Cr}$ compounds, $\mathrm{Cu}, \mathrm{As}, \mathrm{Pb}, \mathrm{Cd}, \mathrm{Hg}, \mathrm{Ni}$ and $\mathrm{Co}$ also add woe to the increased adversity on the aquatic life forms. The increased temperature, turbidity, $\mathrm{pH}$ fluctuation and oxygen depletion proves to be lethal to living forms directly or indirectly [6]. Textile dye effluents were highly fluctuating in chemical oxygen demand, biological oxygen demand, $\mathrm{pH}$, salinity, conductivity, organic and inorganic salts used in different stages of textile dye processing $[7,8]$. Various components of TDEs including salts, surfactants and chlorinated compounds were main pollutants [9].

In the present study the influence of different TDE $\left(\mathrm{ST}_{1}, \mathrm{ST}_{2}, \mathrm{ST}_{3}, \mathrm{ST}_{4}, \mathrm{ST}_{5}\right.$ and $\mathrm{ST}_{6}$ ) of Pallipalayam area of Namakkal district were analyzed and their influence on the acetylcholine esterase and alkaline phosphatase activity of $B$. geminata were evaluated. The larvae of dragonflies were aquatic forms and were found to be good ecological indicators in water quality monitoring [10]. The larvae were being used as bio-indicators as their physiology and biochemistry were highly responsive to metal pollution in aquatic environment [11-14].

\section{Materials and Methods}

\section{Collection and Characterization of the Textile Dye Effluent Samples}

The major points of confluence of textile dyeing effluents such as Aavarankadu ( $\left.\mathrm{ST}_{1}\right)$, Pallipalayam ( $\left.\mathrm{ST}_{2}\right)$, Aavathipalayam $\left(\mathrm{ST}_{3}\right)$, Komarapalayam $\left(\mathrm{ST}_{4}\right)$, Vediyarasanpalayam $\left(\mathrm{ST}_{5}\right)$ and Kaliyanur $\left(\mathrm{ST}_{6}\right)$ of Namakkal District, Tamil Nadu, India were selected and effluent samples were collected using clean reagent bottles and brought to the laboratory and the physicochemical parameters were carried out to determine colour, odour, $\mathrm{pH}$, electrical conductivity, BOD,COD, TSS, chemical components such as potassium and metals like cadmium, lead, chromium etc. using standard methods specified by APHA, [15]. After finding out the $\mathrm{LC}_{50}$ value for each effluent, suitable sub lethal concentrations were prepared.

\section{Collection and Identification of Larval Stages of Bradinopyga Geminata}

The different larval stages of dragonfly larvae were collected from their natural breeding places like agricultural tanks in and around Trichengode of Namakkal District, Tamil Nadu, India with the help of aquarium nets and brought to the laboratory by a clean glass jars. The larvae of B. geminata have short antennae, conspicuous bead like compound eyes and long narrow abdomen with peculiar abdominal gills. A prehensile labium makes these species unique which was used as food capturing apparatus. The dorsal side was brownish green and the ventral side was pale in colour. They were hemi-metabolous with approximately fifteen larval stages before it reach its adulthood under the standard living conditions. They attain a total length of $21 \mathrm{~mm}$ in their final larval instar stage, $16 \mathrm{~mm}$ and $12 \mathrm{~mm}$ in their penultimate and antepenultimate stage [10].

\section{Determination of Acetyl Choline Esterase (Ache) Activity}

\section{Sample Preparation - Hemolymph}

Hemolymph was drawn from the larvae into Eppendorff Pipette containing 0.1 to 0.5 milligrams of phenoloxidase inhibitor (phenylthiourea) to prevent tanning and then diluted $5 \times$ with saline solution of $0.7 \%$. The hemolymph samples were then centrifuged at 2000 rpm for 5 minutes, and only the supernatant fractions were used for assay.

\section{Sample Preparation-Nervous Tissue}

The brain and ventral nerve cord along with three thoracic and three abdominal ganglia of larvae were dissected out for enzyme assay by placing them in an ice bath at $4 \pm 1^{\circ} \mathrm{C}$. It was homogenized in $5 \mathrm{ml}$ of phosphate buffer ( $\mathrm{pH}$ 7.8) for $2 \mathrm{~min}$, in an ice chilled glass homogenizer. For acid and alkaline phosphatase, the tissues were homogenized in $2 \mathrm{ml}$ of citrate buffer ( $\mathrm{pH} 4.8$ ) and alkaline buffer ( $\mathrm{pH} 10.5$ ) respectively for $2 \mathrm{~min}$ in an ice chilled glass homogenizer. The homogenates were transferred to glass centrifuge tubes and spun at $3250 \mathrm{~g}$ at $4 \mathrm{oC}$. The supernatants were used directly as an enzyme source. Acetylcholinesterase activity was determined by Sigma colorimetric determination at $25^{\circ} \mathrm{C}$ for 30 minutes (Sigma Technical Bulletin, 420).

\section{Statistical Analyses}

The data obtained from the present investigation were tabulated, statistically analyzed. Two-way analyses of variance (ANOVA) were calculated using SPSS (version No.10) to test the level of significance of difference between various effluents of different stations. 


\section{Results and Discussion}

The prime function of acetylcholine esterase is to hydrolyse carboxylic esters and promoting the transmission of nerve impulses in all organisms including insects [16,9]. It plays an important role in synaptic transmission in insects [17]. As the toxic pollutants inhibit the action hydroxylation of the neurotransmitter acetylcholine at the synaptic terminals to acetate and choline, it can be used as a biomarker in toxicological studies [18]. In the present work the activity of the acetylcholine esterase was found elevated in all the concentrations of the textile effluents of all the stations than the control.
The activity of the enzyme of control larvae of Antepenultimate, penultimate and final instars were observed $\quad 3.22 \pm 0.51 \mu / \mathrm{mg}, \quad 3.35 \pm 0.71 \mu / \mathrm{mg}$ and $4.68 \pm 0.77 \mu / \mathrm{mg}$ respectively. There was an increasing trend of the AChE level, noticed with increasing concentrations of the effluents of all the stations. Among all the stations the ST5 shows an increased activity of AChE in the larvae of Antepenultimate and penultimate were observed as $5.85 \pm 0.94 \mu / \mathrm{mg}$ and $5.85 \pm 0.98 \mu / \mathrm{mg}$ respectively. The values are significant at $5 \%(\mathrm{P}<0.05)$ level (Tables 1 and 2). Whereas the hyper activity AChE of the final instar larvae were estimated as $5.71 \pm 0.45 \mu / \mathrm{mg}$ in $2.4 \%$ of concentration is non-significant $(\mathrm{P}>0.05)$ (Table 3).

\begin{tabular}{|c|c|c|c|c|c|c|c|c|c|}
\hline \multirow{2}{*}{ S No } & \multirow{2}{*}{ Stations } & \multicolumn{6}{|c|}{ Activity of the acetylcholine esterase in different concentrations of the TDE } & P value \\
\cline { 3 - 9 } & & $\begin{array}{c}\text { Control } \\
\mathbf{( 0 \% )}\end{array}$ & $\mathbf{0 . 4 0 \%}$ & $\mathbf{0 . 8 0 \%}$ & $\mathbf{1 . 2 0 \%}$ & $\mathbf{1 . 6 0 \%}$ & $\mathbf{2 . 0 0 \%}$ & $\mathbf{2 . 4 0 \%}$ & \multirow{2}{*}{$(<\mathbf{0 . 0 5 )}$} \\
\hline 1 & ST 1 & $3.22 \pm 0.51$ & $3.58 \pm 0.75$ & $3.70 \pm 0.45$ & $3.85 \pm 0.84$ & $4.25 \pm 0.84$ & $4.86 \pm 0.78$ & $5.62 \pm 0.44$ & \\
\hline 2 & ST 2 & $3.22 \pm 0.51$ & $3.60 \pm 0.12$ & $3.76 \pm 0.15$ & $3.98 \pm 0.64$ & $4.02 \pm 0.65$ & $4.15 \pm 0.62$ & $4.28 \pm 0.72$ \\
\hline 3 & ST 3 & $3.22 \pm 0.51$ & $3.72 \pm 0.45$ & $3.94 \pm 0.40$ & $4.25 \pm 0.52$ & $4.84 \pm 0.46$ & $5.13 \pm 0.45$ & $5.54 \pm 0.81$ & \multirow{2}{*}{$0.0001^{*}$} \\
\hline 4 & ST 4 & $3.22 \pm 0.51$ & $3.67 \pm 0.85$ & $3.88 \pm 0.15$ & $4.13 \pm 0.80$ & $4.54 \pm 0.18$ & $4.90 \pm 0.61$ & $5.40 \pm 0.65$ \\
\hline 5 & ST 5 & $3.22 \pm 0.51$ & $3.95 \pm 0.65$ & $4.14 \pm 0.78$ & $4.65 \pm 0.59$ & $4.86 \pm 0.43$ & $5.15 \pm 0.84$ & $5.85 \pm 0.94$ \\
\hline 6 & ST 6 & $3.22 \pm 0.51$ & $3.54 \pm 0.70$ & $3.87 \pm 0.46$ & $4.10 \pm 0.45$ & $4.45 \pm 0.55$ & $5.13 \pm 0.95$ & $5.68 \pm 0.25$ & \\
\hline
\end{tabular}

Table 1: Estimation of acetyl choline esterase $(\mu \mathrm{G} / \mathrm{mg})$ in the head of antepenultimate larval instar of dragonfly Bradinopyga Geminata in different concentrations of textile effluents to 15 days of exposure. Two-way ANOVA of acetyl choline esterase in head of antepenultimate larval instar.

Significant $(\mathrm{P}<0.05)$

Non-significant $(\mathrm{P}>0.05)$

\begin{tabular}{|c|c|c|c|c|c|c|c|c|c|}
\hline S No & Stations & $\begin{array}{c}\text { Control } \\
(0 \%)\end{array}$ & $0.40 \%$ & $0.80 \%$ & $1.20 \%$ & $1.60 \%$ & $2.00 \%$ & $2.40 \%$ & $\begin{array}{c}\text { P value } \\
(<0.05)\end{array}$ \\
\hline 1 & ST 1 & $3.35 \pm 0.71$ & $3.78 \pm 0.75$ & $4.01 \pm 0.65$ & $4.11 \pm 0.85$ & $4.33 \pm 1.05$ & $5.51 \pm 0.45$ & $5.65 \pm 1.02$ & \multirow{4}{*}{$0.0001^{*}$} \\
\hline 2 & ST 2 & $3.35 \pm 0.71$ & $3.41 \pm 0.40$ & $3.52 \pm 0.68$ & $3.88 \pm 0.82$ & $4.10 \pm 1.10$ & $5.35 \pm 1.08$ & $5.49 \pm 0.78$ & \\
\hline 5 & ST 5 & $3.35 \pm 0.71$ & $3.60 \pm 0.93$ & $3.71 \pm 0.75$ & $3.95 \pm 0.91$ & $4.11 \pm 1.20$ & $5.30 \pm 1.24$ & $5.85 \pm 0.98$ & \\
\hline 6 & ST 6 & $3.35 \pm 0.71$ & $4.07 \pm 0.65$ & $4.22 \pm 0.84$ & $4.38 \pm 0.75$ & $4.52 \pm 0.96$ & $5.66 \pm 0.84$ & $5.71 \pm 1.20$ & \\
\hline
\end{tabular}

Table 2: Estimation of Acetyl Choline Esterase $(\mu \mathrm{g} / \mathrm{Mg})$ in the Head in Penultimate Larval Instar of Dragonfly Bradinopyga Geminata in Different Concentrations of Textile Effluents to 15 Days of Exposure.

Two-way ANOVA of acetyl choline esterase in head of penultimate larval instar.

Significant $(\mathrm{P}<0.05)$

Non-significant $(\mathrm{P}>0.05)$ 


\section{International Journal of Zoology and Animal Biology}

\begin{tabular}{|c|c|c|c|c|c|c|c|c|c|}
\hline \multirow{2}{*}{ S No } & \multirow{2}{*}{ Stations } & \multicolumn{7}{|c|}{ Activity of the acetylcholine esterase in different concentrations of the TDE } & \multirow{2}{*}{$\frac{P \text { value }}{(<0.05)}$} \\
\hline & & Control (0\%) & $0.40 \%$ & $0.80 \%$ & $1.20 \%$ & $1.60 \%$ & $2.00 \%$ & $2.40 \%$ & \\
\hline 1 & ST 1 & $4.68 \pm 0.77$ & $4.75 \pm 0.60$ & $4.84 \pm 0.51$ & $4.98 \pm 0.82$ & $5.15 \pm 0.45$ & $5.42 \pm 0.75$ & $5.67 \pm 0.51$ & \multirow{6}{*}{$0.08^{* *}$} \\
\hline 2 & ST 2 & $4.68 \pm 0.77$ & $4.70 \pm 0.55$ & $4.68 \pm 0.45$ & $4.90 \pm 0.62$ & $5.10 \pm 0.85$ & $5.30 \pm 0.35$ & $5.38 \pm 0.84$ & \\
\hline 3 & ST 3 & $4.68 \pm 0.77$ & $4.72 \pm 0.75$ & $4.76 \pm 0.75$ & $4.95 \pm 0.75$ & $5.20 \pm 0.95$ & $5.38 \pm 0.61$ & $5.45 \pm 0.62$ & \\
\hline 4 & ST 4 & $4.68 \pm 0.77$ & $4.70 \pm 0.52$ & $4.85 \pm 0.15$ & $4.37 \pm 0.45$ & $4.78 \pm 0.45$ & $5.21 \pm 0.51$ & $5.42 \pm 0.85$ & \\
\hline 5 & ST 5 & $4.68 \pm 0.77$ & $4.78 \pm 0.50$ & $4.15 \pm 0.45$ & $4.85 \pm 0.81$ & $5.02 \pm 0.85$ & $5.32 \pm 0.84$ & $5.71 \pm 0.45$ & \\
\hline 6 & ST 6 & $4.68 \pm 0.77$ & $4.70 \pm 0.18$ & $4.78 \pm 0.55$ & $5.02 \pm 0.61$ & $5.28 \pm 0.75$ & $5.45 \pm 0.75$ & $5.60 \pm 0.74$ & \\
\hline
\end{tabular}

Table 3: Estimation of Acetyl Choline Esterase ( $\mu \mathrm{g} / \mathrm{Mg})$ in the Headoffinal Larval Instar of Insect Dragonfly Bradinopyga Geminatai Different Concentrations of Textile Effluents to 15 Days of Exposure.

Two-way ANOVA of acetyl choline esterase in head of final larval instar.

Significant $(\mathrm{P}<0.05)$

Insignificant $(\mathrm{P}>0.05)$

It may be due to the fact that the increased level of acetylcholine could be triggered by variation in water temperature, concentration of the dissolved oxygen and the impact of pollutants in the surrounding environments by industrial effluents [19].

It is also evident that endocrinological alterations and inflated water temperature might have been the reason for the higher activity of the acetyl cholinesterase activity in the aquatic larvae [19].

In order to enhance the impaired nerve conduction under the textile dyeing effluent stress, the feed-back mechanism of the organism might have attempted to produce more acetylcholine esterase as a reciprocal act to give a biochemical thrust to get the function done [18].

Similarly it was also expected that the dye residues, heavy metals and other auxiliary chemicals present in the TDE, also interfere with the activity of AChE in the experimental insects. According to Wanyama, et al. and Blecharz, et al. $[20,21]$ who observed that the excessive use of metal based salts like aluminuim, manganese etc. to increase the luster of fabrics, increase the metal ions in the industrial effluents. Such heavy metal contamination of the water may lead to the increased activity of AChE $[22,23]$. Hence, it could be concluded that the acetyl cholinesterase activity was increased due to the heavy metal contaminations by TDE.

\section{References}

1. Herman PB, Fletcher JM (1966) Textile Dyeing, Part I serial 5508A, International Textbook company, Pennsylvania, USA, pp: 3-4.
2. Rannung U, Bramstedt H, Nilsson U (1992) The presence of genotoxic and bioactive components in indigo dyed fabrics: a possible health risk. Mut Res 282(3): 45-53.

3. Wollin KM, Gorlitz BD (2004) Comparison of genotoxicity of textile dyestuffs in Salmonella mutagenicity assay, in vitro micronucleus assay, and single cell gel/comet assay. J Environ Pathol Toxicol Oncol 23(4): 267-278.

4. Birhanli A, Ozmen M (2005) Evaluation of toxicity and Teratogenicity of six commercial textile dyes using the frog embryo teratogenesis assay-Xenopus. Drug and Chemical Toxicologies 28(1): 51-65.

5. Bertea A, Bertea AP (2008) Decolonization and recycling of textile wastewater (in Romanian), Performantica Ed, Iasi, Romania.

6. Elango G (2017) Physico-Chemical Parameters of Textile Dyeing Effluent and Its Impacts with Case study. Int J Res Chem Environ 7(1): 17-24.

7. Dos SAB, Cervantes FJ, Van LJB (2007) Review paper on current technologies for decolourisation of textile wastewaters: Perspectives for anaerobic biotechnology. Bioresour Technol 98(12): 23692385.

8. Talarposhti AM, Donnelly T, Anderson GK (2001) Colour removal from a simulated dye wastewater using a two-phase anaerobic packed bed reactor. Water Research 35(2): 425-432.

9. Ben Mansour H, Houas I, Montassar F, Ghedira K, Barillier D, et al. (2012) Alteration of in vitro and 


\section{International Journal of Zoology and Animal Biology}

acute in vivo toxicity of textile dyeing wastewater after chemical and biological remediation. Environ Sci Pollut Res Int 19(7): 2634-2643.

10. Thangaraj A, Muralidharan S, Senthilkumar A, Moorthi M (2017) The physico-chemical characteristics of different textile dyeing effluents and their influence on the total protein levels of dragonfly larvae Bradinopyga Geminata. International Journal of Scientific and Research 7(7): 534-538.

11. Davis AJ, Hollowary JD, Huijbregts H, Krikken J, KirkSpriggs AH, et al. (2001) Dung beetles as indicators of change in the forests of northern Borneo. Journal of Applied Ecology 38(3): 593-616.

12. Saunders DL, Meeuwig JJ, Vincent ACJ (2002) Freshwater protected areas: Strategies for Conservation. Cons Biol 16(1): 30-41.

13. Chen TB, Zheng YM, Lei M, Huang ZC, Wu HT, et al. (2005) Assessment of heavy metal pollution in surface soils of urban parks in Beijing, China. Chemosphere 60(4): 542-551.

14. Lee CS, Li X, Shi W, Cheung SCN, Thornton I (2006) Metal contamination in urban, sub-urban, and country park soils of Hong Kong: a study based on GIS and multivariate statistics. Sci Total Environ 356(13): 45-61.

15. American Public Health Association (2005) Standard methods for the examination of water and waste water, 21st (edn) American water works association, Water Environment Federation, Washington DC.

16. Charlotte SJ, Lone G, Erik B (1997) Acetylcholinesterase inhibition and altered locomotor behavior in the carabid beetle pterostichus cupreus. A linkage between biomarkers at two levels of biological complexity. Environmental Toxicology and Chemistry 16(8): 1727-1732.

17. Toutant JP (1989) Insect acetylcholine esterase: catalytic properties, tissue distribution and molecular forms. Prog Neurobiol (32): 423-446.

18. McGleenon B, Dynan KB, Passmore AP (1999) Acetyl cholinesterase inhibitors in Alzheimer's disease. $\mathrm{Br} J$ Clin Pharmacol 48(4): 471-480.

19. Rattner BA, Fairbrother A (1991) Biological variability and the influence of stress on cholinesterase activity. Book chapter, Elsevier Science Publishers, pp: 89-107.

20. Wanyama PAG, Kiremire BT, Ogwok P, Murumu JS (2010) The Effect of Different Mordants on Strength and Stability of Colour Produced from Selected DyeYielding Plants in Uganda. International Archive of Applied Sciences and Technology 1(2): 81-92.

21. Blecharz KK, Piechal A, Joniec MI, Pyrzanowska J, Widy TE (2012) Effect of intranasal manganese administration on neurotransmission and spatial learning in rats. Toxicol Appl Pharmacol 265(1): 1-9.

22. Vahid YB, Leila S, Kobra S, Ali AM, Mohammad R (2014) The Toxic Effect of Manganese on the Acetylcholinesterase Activity in Rat Brains. Journal of Toxicology, pp: 4.

23. Maheswari SL, Venkatakrishna MR, Balaji R (2014) Aluminium induced choline toxicity in zebra fish brain - A sequel of oxidative stress. International Journal of Advanced Research 2(2): 322-335. 